\title{
TTR
}

Traduction, terminologie, re?daction

\section{The Translator's Task, Walter Benjamin (Translation)}

\section{Steven Rendall}

Volume 10, numéro 2, 2e semestre 1997

L'essai sur la traduction de Walter Benjamin : traductions critiques

Walter Benjamin's Essay on Translation: Critical Translations

URI : https://id.erudit.org/iderudit/037302ar

DOI : https://doi.org/10.7202/037302ar

Aller au sommaire du numéro

Éditeur(s)

Association canadienne de traductologie

ISSN

0835-8443 (imprimé)

1708-2188 (numérique)

Découvrir la revue

Citer cet article

Rendall, S. (1997). The Translator's Task, Walter Benjamin (Translation). TTR, 10(2), 151-165. https://doi.org/10.7202/037302ar d'utilisation que vous pouvez consulter en ligne.

https://apropos.erudit.org/fr/usagers/politique-dutilisation/ 


\section{The Translator's Task Walter Benjamin}

\section{Translated by Steven Rendall}

When seeking knowledge of a work of art or an art form, it never proves useful to take the receiver into account. Not only is every effort to relate art to a specific public or its representatives misleading, but the very concept of an "ideal" receiver is spurious in any discussion concerning the theory of art, since such discussions are required to presuppose only the existence and essence of human beings. Art itself also presupposes man's corporal and spiritual essence - but no work of art presupposes his attention. No poem is meant for the reader, no picture for the beholder, no symphony for the audience.

Is a translation meant for readers who do not understand the original? That would seem sufficient to explain the differing status of original and translation in the domain of art. In any event, it appears to be the only possible reason for saying "the same thing" over again. What does a poem "say," then? What does it communicate? Very little, to a person who understands it. Neither message nor statement is essential to it. However, a translation that seeks to transmit something can transmit nothing other than a message - that is, something inessential. And this is also the 
hallmark of bad translations. But what then is there in a poem and even bad translators concede this to be essential - besides a message? Isn't it generally acknowledged to be the incomprehensible, the secret, the "poetic"? That which the translator can render only insofar as he - also writes poetry? This in fact leads to another distinguishing mark of bad translation, which can be defined as inexact transmission of an inessential content. And we never get beyond this, so long as translation claims to serve the reader. If it were intended for the reader, then the original would also have to be intended for the reader. If the original is not created for the reader's sake, then how can this relationship allow us to understand translation?

Translation is a mode. In order to grasp it as such, we have to go back to the original. For in it lies translation's law, decreed as the original's translatability. The question of a work's translatability has two senses. It can mean: will it ever find, among the totality of its readers, an adequate translator? Or, more pertinently, whether by its very essence it allows itself to be translated, and hence - in accord with the meaning of this mode - also calls for translation. In principle, the first question can be answered only in a problematic manner, the second apodictically. Only superficial thinking will, by denying the independent sense of the second question, declare them to have the same meaning. In opposition to this it must be pointed out that certain relational concepts gain their proper, indeed their best sense, when they are not from the outset connected exclusively with human beings. Thus we could still speak of an unforgettable life or moment, even if all human beings had forgotten it. If the essence of such lives or moments required that they not be forgotten, this predicate would not be false, it would merely be a demand to which human beings had failed to respond, and at the same time, no doubt, a reference to a place where this demand would find a response, that is, a reference to a thought in the mind of God. The translatability of linguistic constructions would accordingly have to be taken into consideration even if they were untranslatable by human beings. 
And mustn't they actually be untranslatable to a certain degree, if a rigorous concept of translation is applied? In that case we must ask whether the translation of certain linguistic constructions is required. For this proposition is relevant here : if translation is a mode, then translatability must be essential to certain works.

Translation is properly essential to certain works : this does not mean that their translation is essential for themselves, but rather that a specific significance inherent in the original texts expresses itself in their translatability. It is clear that a translation, no matter how good, cannot have any significance for the original. Nevertheless, it stands in the closest connection with the original by virtue of the latter's translatability. Indeed, this connection is all the more intimate because it no longer has any significance for the original itself. It can be called a natural connection, and more precisely a vital connection. Just as expressions of life are connected in the most intimate manner with the living being without having any significance for the latter, a translation proceeds from the original. Not indeed so much from its life as from its "afterlife" or "survival" [Überleben]. Nonetheless the translation is later than the original, and in the case of the most significant works, which never find their chosen translators in the era in which they are produced, indicates that they have reached the stage of their continuing life [Fortleben]. The notion of the life and continuing life of works of art should be considered with completely unmetaphorical objectivity. Even in ages of the most prejudiced thinking it has been suspected that life must not be attributed to organic corporeality alone. But there can be no question of extending its dominion under the feeble aegis of the soul, as Fechner attempted to do; not to mention defining life on the basis of still less decisive aspects of animal life such as sensitivity, which betokens life only occasionally. Rather, it is only when life is attributed to everything that has a history, and not to that which is only a stage setting for history, that this concept comes into its own. For the range of the living must ultimately be delimited on the basis of history and not of nature, without 
mentioning such unstable notions as sensitivity and soul. From this arises the philosopher's task, which is to understand all natural life on the basis of the more comprehensive life of history. And isn't the continuing life of works incomparably easier to recognize than that of creatures? The history of great works of art knows about their descent from their sources, their shaping in the age of the artists, and the periods of their basically eternal continuing life in later generations. Where it appears, the latter is called fame. Translations that are more than transmissions of a message are produced when a work, in its continuing life, has reached the age of its fame. Hence they do not so much serve the work's fame (as bad translators customarily claim) as owe their existence to it. In them the original's life achieves its constantly renewed, latest and most comprehensive unfolding.

As the unfolding of a special, high form of life, this unfolding is determined by a special, high purposefulness. Life and purposefulness - the connection between them seems easily accessible but nevertheless almost escapes knowledge, disclosing itself only where that purpose, toward which all the particular purposes of life tend, ceases to be sought in its own sphere, and is sought instead in a higher one. All purposeful phenomena of life, as well as life's purposefulness itself, are in the final analysis purposeful not for life, but for the expression of its essence, for the representation of its significance. Thus translation ultimately has as its purpose the expression of the most intimate relationships among languages. Translation cannot possibly reveal or produce this hidden relationship; however, translation can represent this relationship, insofar as it realizes it seminally or intensively. In fact, this representation of the intended object by means of an incomplete form or seed of its production is a very special mode of representation seldom to be encountered in the domain of nonlinguistic life. For in analogies and signs non-linguistic life has types of reference other than intensive, that is, anticipatory, intimating realization. - This imagined, inner relationship among languages is, however, a relationship of special convergence. It 
consists in the fact that languages are not alien to each other, but a priori, and independently of all historical connections, related to each other in what they want to say.

With this attempt at an explanation the discussion seems clearly to have come out, after futile detours, at the traditional theory of translation. If the relationship among languages is to demonstrate itself in translations, how could it do so except by conveying the form and sense of the original as accurately as possible? Of course, the traditional theory would scarcely be able to define this concept of accuracy, and thus could give no account of what is essential to translation. In truth, however, the relationship among languages shows itself in translations to be far deeper and more definite than in the superficial and indefinable similarity of two literary texts. To grasp the true relationship between original and translation, we must undertake a line of thought completely analogous, in its goal, to those taken by critical epistemology in demonstrating the impossibility of a reflection theory. Just as in critical epistemology it is shown that there can be no objective knowledge, or even the claim to such knowledge, if the latter consists in reflections of the real, so here it can be shown that no translation would be possible if, in accord with its ultimate essence, it were to strive for similarity to the original. For in its continuing life, which could not be so called if it were not the transformation and renewal of a living thing, the original is changed. Established words also have their after-ripening. What might have been the tendency of an author's poetic language in his own time may later be exhausted, and immanent tendencies can arise anew out of the formed work. What once sounded fresh may come to sound stale, and what once sounded idiomatic may later sound archaic. To seek what is essential in such transformations, as well as in the equally constant transformations of sense, in the subjectivity of later generations rather than in the inner life of language and its works, would be - even granting the crudest psychologism - to confuse the ground and the essence of a thing; or, putting it more strongly, it would be to deny, out of an 
impotence of thought, one of the most powerful and fruitful historical processes. Even if one were to consider the last stroke of the author's pen the work's coup de grâce, that would not suffice to save this dead theory of translation. For just as the tone and significance of great literary works are completely transformed over the centuries, the translator's native language is also transformed. Indeed, whereas the poetic word endures in its own language, even the greatest translation is destined to be taken up into the growth of its language and perish as a result of its renewal. Far from being a sterile similarity between two languages that have died out, translation is, of all modes, precisely the one called upon to mark the after-ripening of the alien word, and the birth pangs of its own.

If the kinship of languages manifests itself in translation, it does so otherwise than through the vague similarity of original and copy. For it is clear that kinship does not necessarily involve similarity. In this context the notion of kinship is in accord with its narrower usage, to the extent that in both cases it cannot be adequately defined by similarity of origin, although the concept of origin remains indispensable in defining the narrower usage. Wherein can the kinship of two languages be sought, apart from a historical kinship? No more in the similarity of literary texts than in the similarity of their words. All suprahistorical kinship of languages consists rather in the fact that in each of them as a whole, one and the same thing is intended; this cannot be attained by any one of them alone, however, but only by the totality of their mutually complementary intentions : pure language. Whereas all the particular elements of different languages - words, sentences, structures - are mutually exclusive, these languages complement each other in their intentions. To gain a precise understanding of this law, one of the most fundamental laws of the philosophy of language, it is necessary to distinguish, within intention, the intended object from the mode of its intention. In "Brot" and "pain," the intended object is the same, but the mode of intention differs. It is because of their modes of intention that the two words 
signify something different to a German or a Frenchman, that they are not regarded as interchangeable, and in fact ultimately seek to exclude one another; however, with respect to their intended object, taken absolutely, they signify one and the same thing. Thus whereas these two words' modes of intention are in conflict, they complement each other in the two languages from which they stem. And indeed in them the relation between the mode of intention and the intended object is complemented. In the individual, uncomplemented languages, the intended object is never encountered in relative independence, for instance in individual words or sentences, but is rather caught up in constant transformation, until it is able to emerge as pure language from the harmony of all these modes of intention. Until then it remains hidden in the various languages. But if languages grow in this way until they reach the messianic end of their history, then it is translation that is ignited by the eternal continuing life of the work and the endless revival of languages in order to constantly test this sacred growth of languages, to determine how distant what is hidden within them is from revelation, how close it might become with knowledge of this distance.

To say this is of course to admit that translation is merely a preliminary way of coming to terms with the foreignness of languages to each other. A dissolution of this foreignness that would not be temporal and preliminary, but rather instantaneous and final, remains out of human reach, or is at least not to be sought directly. Indirectly, however, the growth of religions ripens into a higher language the seed hidden in languages. Thus translation, although it cannot claim that its products will endure, and in this respect differs from art, does not renounce its striving toward a final, ultimate, and decisive stage of all linguistic development. In translation the original grows into a linguistic sphere that is both higher and purer. It cannot, however, go on living indefinitely in this sphere, since it is far from attaining it in all parts of its form; but it nevertheless at least points, with wonderful penetration, toward the predetermined, inaccessible 
domain where languages are reconciled and fulfilled. The original does not attain this domain in every respect, but in it lies that which, in a translation, is more than a message. This essential kernel can be more precisely defined as what is not retranslatable in a translation. One can extract from a translation as much communicable content as one wishes, and this much can be translated; but the element toward which the genuine translator's efforts are directed remains out of reach. It is not translatable, like the literary language of the original, because the relation between content and language in the original is entirely different from that in the translation. In the original, content and language constitute a certain unity, like that between a fruit and its skin, whereas a translation surrounds its content as if with the broad folds of a royal mantle. For translation indicates a higher language than its own, and thereby remains inappropriate, violent, and alien with respect to its content. This fracture hinders any further translation, and at the same time renders it superfluous. For every translation of a work at a specific point in the history of language represents, with respect to a specific aspect of its content, translation into all other languages. Thus translation transplants the original into an ironically - more ultimate linguistic domain, since it cannot be displaced from it by any further translation, but only raised into it anew and in other parts. It is not for nothing that the word "ironically" reminds us here of Romantic modes of thought. The Romantics, more than any others, gained insight into the life of works of art, to which translation bears the highest witness. The Romantics, of course, hardly recognized the significance of translation, turning their attention instead entirely toward criticism, which also represents a genuine, though narrower, element in the work's continuing life. But even if their theory was not much inclined to focus on translation, their great translation work itself was accompanied by a sense of the essence and dignity of this mode. This feeling - everything points to this - need not be at its strongest in the poet; it may in fact play the smallest role in him qua poet. History certainly does not suggest that major translators are poets and minor poets are mediocre translators, as is generally 
believed. Many of the greatest, such as Luther, Voss, and Schlegel, are incomparably more important as translators than as poets, and others, such as Hölderlin and George, cannot be adequately described solely as poets when the whole range of their work and especially their translations - is taken into account. Just as translation is a distinctive mode, the translator's task may also be conceived as distinctive and clearly differentiated from the poet's.

The translator's task consists in this : to find the intention toward the language into which the work is to be translated, on the basis of which an echo of the original can be awakened in it. Here we encounter a characteristic of translation that decisively distinguishes it from the poetic work, because the latter's intention never is directed toward language as such, in its totality, but solely and immediately toward certain linguistic structurings of content. However, unlike a literary work, a translation does not find itself, so to speak, in middle of the high forest of the language itself; instead, from outside it, facing it, and without entering it, the translation calls to the original within, at that one point where the echo in its own language can produce a reverberation of the foreign language's work. Its intention is not only directed toward an object entirely different from that of the poetic work, namely toward a language as a whole, starting out from a single work of art, but is also different in itself : the poet's intention is spontaneous, primary, concrete, whereas the translator's is derivative, final, ideal. For the great motive of integrating the plurality of languages into a single true language is here carrying out its work. In this integration individual propositions, poetic structures, and judgments never arrive at agreement (since they remain dependent on translation); it is rather the languages themselves that agree, complemented and reconciled with each other in their mode of intention. If there is nevertheless a language of truth, in which the ultimate secrets toward which all thinking strives are stored up, at peace and even silent, then this language of truth is - "the true language." And in fact this language, in the anticipation and description of which lies the only perfection 
philosophy can hope to achieve, is concealed intensively in translations. There is no muse of philosophy, and there is also no muse of translation. They are not, however, philistine, as sentimental artistic folk would like to think. For there is a philosophical genius, whose essential characteristic is the longing for the language that is announced in translation. "Les langues imparfaites en cela que plusieurs, manque la suprême: penser étant écrire sans accessoires, ni chuchotement mais tacite encore l'immortelle parole, la diversité, sur terre, des idiomes empêche personne de proférer les mots qui, sinon se trouveraient, par une frappe unique, elle-même matériellement la vérité." If what Mallarme conceives in these words is rigorously applied to the philosopher, then translation, with its seeds of such a language, stands half-way between poetry and doctrine. Translation's work is less prominent than doctrine's, but it puts its mark on history no less deeply.

If the translator's task is regarded in this light, then the paths to its fulfillment threaten to become all the more impenetrably dark. Indeed, this task - that of bringing the seeds of pure speech to ripeness in translation - seems impossible to accomplish, determinable in no realization. And isn't the ground cut out from under any such realization if the reproduction of meaning is no longer the criterion? Viewed negatively, that is precisely the import of all the foregoing. Fidelity and freedom the freedom of rendering in accord with the meaning, and in its service, fidelity in opposition to the word - these are the old, traditional concepts in every discussion of translation. They no longer seem useful for a theory that seeks in translation something other than the reproduction of meaning. Indeed, used in the conventional way, they are perpetually caught up in an irresolvable conflict. What precisely can fidelity actually contribute to the reproduction of meaning? Fidelity in translating the individual word can almost never fully render the meaning it has in the original. For this meaning is fully realized in accord with its poetic significance for the original work not in the intended object, but 
rather precisely in the way the intended object is bound up with the mode of intention in a particular word. It is customary to express this by saying that words carry emotional connotations. In reality, with regard to syntax, word-for-word translation completely rejects the reproduction of meaning and threatens to lead directly to incomprehensibility. For the nineteenth century, Hölderlin's translations of Sophocles represented a monstrous example of this kind of literalness. Finally, it is self-evident that fidelity in rendering form makes rendering meaning more difficult. Hence the demand for literalness cannot be deduced from the interest in maintaining meaning. The latter serves the undisciplined license of bad translators far more than it serves poetry and language. Therefore this demand, whose justice is obvious and whose ground is deeply concealed, must necessarily be understood on the basis of more pertinent relationships. Just as fragments of a vessel, in order to be fitted together, must correspond to each other in the tiniest details but need not resemble each other, so translation, instead of making itself resemble the meaning of the original, must lovingly, and in detail, fashion in its own language a counterpart to the original's mode of intention, in order to make both of them recognizable as fragments of a vessel, as fragments of a greater language. For that very reason translation must in large measure turn its attention away from trying to communicate something, away from meaning; the original is essential to translation only insofar as it has already relieved the translator and his work of the burden and organization of what is communicated. En arche hen ho logos, in the beginning was the word : this is also valid in the realm of translation. On the other hand, the translation's language can, indeed must free itself from bondage to meaning, in order to allow its own mode of intentio to resound, not as the intentio to reproduce, but rather as harmony, as a complement to its language in which language communicates itself. Hence reading a translation as if it were an original work in the translation's own language is not the highest form of praise, especially in the age when the translation is produced. On the contrary, the meaning of the fidelity ensured by literal translation is that the great longing 
for the completion of language is expressed by the work. True translation is transparent, it does not obscure the original, does not stand in its light, but rather allows pure language, as if strengthened by its own medium, to shine even more fully on the original. This is made possible above all by conveying the syntax word-for-word, and this demonstrates that the word, not the sentence, is the original element of translation. For the sentence is the wall in front of the language of the original, and word-for-word rendering is the arcade.

While fidelity and freedom in translation have long been seen as conflicting tendencies, it also seems that this deeper interpretation of one of them does not reconcile the two, but on the contrary denies the other any justification. For what can the point of freedom be, if not the reproduction of meaning, which is no longer to be regarded as normative? Only if it can be posited that the meaning of a linguistic construction is identical with the meaning of its communication, does something ultimate and decisive remain beyond any message, very near it and yet infinitely distant, hidden under it or clearer, broken by it or more powerful. Beyond the communicable, there remains in all language and its constructions something incommunicable which is, depending on the context in which it is encountered, either symbolizing or symbolized; symbolized however in the development of the languages themselves. And what seeks to be represented and even produced in the development of languages is that kernel of pure language itself. But if this hidden and fragmentary kernel is nevertheless present in life as something symbolized, it inhabits linguistic constructions only as something symbolizing. While this ultimate being, which is therefore pure speech itself, is in languages bound up only with the linguistic and its transformations, in linguistic constructions it is burdened with heavy and alien meaning. Translation alone possesses the mighty capacity to unbind it from meaning, to turn the symbolizing element into the symbolized itself, to recuperate the pure language growing in linguistic development. In this pure language - which 
no longer signifies or expresses anything but rather, as the expressionless and creative word that is the intended object of every language - all communication, all meaning, and all intention arrive at a level where they are destined to be extinguished. And it is in fact on the basis of them that freedom in translation acquires a new and higher justification. Freedom does not gain its standing from the communication's meaning; it is precisely truth's task to emancipate freedom from meaning. Rather, freedom demonstrates in the translation's own language what it can contribute to the service of pure language. To set free in his own language the pure language spellbound in the foreign language, to liberate the language imprisoned in the work by rewriting it, is the translator's task. To this end he breaks through the rotten barriers of his own language : Luther, Voss, Hölderlin, George have all extended the frontiers of the German language. What now remains for the significance of meaning in the relationship between translation and original can be easily summed up in a comparison. Just as a tangent touches a circle fleetingly and at only a single point, and just as this contact, not the point, prescribes the law in accord with which the tangent pursues its path into the infinite, in the same way a translation touches the original fleetingly and only at the infinitely small point of meaning, in order to follow its own path in accord with the law of fidelity in the freedom of linguistic development. Without naming or grounding it, Rudolf Pannwitz has characterized the true significance of this freedom in certain passages of his book Die Krisis der europäischen Kultur which, next to Goethe's remarks in the notes to his Westöstlicher Divan, must be by far the best thing published in Germany on the theory of translation. He writes : "our translations even the best start out from a false principle they want to germanize Indic Greek English instead of indicizing, graecizing, anglicizing German. they are far more awed by their own linguistic habits than by the spirit of the foreign work [...] the fundamental error of the translator is that he holds fast to the state in which his own language happens to be rather than allowing it to be put powerfully in movement by the foreign language. he must in 
particular when he is translating out of a language very distant from his own penetrate back to the ultimate elements of the language at that very point where image tone meld into one he must broaden and deepen his own language through the foreign one we have no notion how far this is possible to what degree each language can transform itself one language differentiates itself from another almost as one dialect from another but this happens not when they are considered all too lightly but only when they are considered with sufficient gravity."

To what extent a translation can correspond to the essence of this mode is determined objectively by the translatability of the original. The less value and dignity its language has, the more it is communication of meaning, the less is to be gained from it for translation, up to the point where the overpowering weight of that meaning, far from being a lever for producing a translation fully in accord with its mode, makes the latter impossible. The higher the work's constitution, the more it remains translatable, in the very fleetingness of its contact with its meaning. This is of course true only of original works. Translations, on the contrary, prove to be untranslatable not because meaning weighs on them heavily, but rather because it attaches to them all too fleetingly. For this as for every other essential aspect, Hölderlin's translations represent a confirmation, particularly his translations of the two Sophoclean tragedies. In them the harmony of languages is so deep that meaning is touched by language only in the way an Aeolian harp is touched by the wind. Hölderlin's translations are prototypes of their mode; they are related to even the most fully realized translations of their texts as a prototype is related to a model, as a comparison of Hölderlin's and Borchardt's translations of Pindar's third Pythian ode shows. For that very reason they, more than all others, are inhabited by the monstrous and original danger of all translation : that the portals of a language broadened and made malleable in this way may close and lock up the translator in silence. The Sophocles translations were Hölderlin's last work. In them meaning plunges from abyss to abyss until it threatens to 
become lost in the bottomless depths of language. But there is a stopping point. It is, however, accorded only to holy scripture, in which meaning has ceased to be the watershed dividing the flow of language from the flow of revelation. Where the text belongs immediately to truth or doctrine, without the mediation of meaning, in its literalness of true language, it is unconditionally translatable. No longer for its own sake, but solely for that of the languages. With regard to this text such boundless trust is required of translation, that just as language and revelation must be united in the text, literalness and freedom must be united in the form of an interlinear translation. For to some degree all great writings, but above all holy scripture, contain their virtual translation between the lines. The interlinear version of the holy scriptures is the prototype or ideal of all translation.

\section{University of Oregon}

Steven Rendall : Quartier de l’Église, 82100 Les Barthes, France. 